九州大学学術情報リポジトリ

Kyushu University Institutional Repository

\title{
Cloning, Sequencing, and Overexpression of Gene Encoding the Bacillus stearothermophilus Lipoate Acetyltransferase
}

\section{Miyata, Takeshi}

Laboratory of Protein Chemistry and Engineering, Department of Genetic Resources Technology, Graduate School of Bioresource and Bioenvironmental Sciences, Kyushu University

Aso, Yoichi

Laboratory of Protein Chemistry and Engineering, Department of Genetic Resources Technology, Faculty of Agriculture, Kyushu University

Satoh, Yutaka

Laboratory of Protein Chemistry and Engineering, Department of Genetic Resources Technology, Graduate School of Bioresource and Bioenvironmental Sciences, Kyushu University

Kita, Masahito

Laboratory of Protein Chemistry and Engineering, Department of Genetic Resources Technology, Graduate School of Bioresource and Bioenvironmental Sciences, Kyushu University

他

https://doi.org/10.5109/24464

出版情報：九州大学大学院農学研究院紀要. 47 (1)，pp.97-107，2002-10-30. Kyushu University バージョン：

権利関係: 


\title{
Cloning, Sequencing, and Overexpression of Gene Encoding the Bacillus stearothermophilus Lipoate Acetyltransferase
}

\author{
Takeshi MIYATA*, Yoichi ASO**, Yutaka SATOH*, Masahito KITA*, \\ Toki FUKUDA*, Tatsuhiko HATTORI*, Toshiro IRIE*, \\ Masatsune ISHIGURO and Fumio MIAKE***
}

\begin{abstract}
Laboratory of Protein Chemistry and Engineering, Department of Genetic Resources Technology, Faculty of Agriculture, Kyushu University, Fukuoka 812-8581, Japan (Received June 26, 2002 and accepted July 12, 2002)
\end{abstract}

\begin{abstract}
Lipoate acetyltransferase (E2) comprising sixty subunits is one of the three component enzymes of pyruvate dehydrogenase multienzyme complex from the thermophile, Bacillus stearothermophilus. Gene encoding E2 of the B. stearothermophilus (NCA 1503) spontaneous mutant was cloned and sequenced. The amino acid sequence of E2 deduced from its nucleotide sequence (1305 bp) was quite similar to that of original strain (GenBank: 40038). The gene was overexpressed in the Escherichia coli BL21 (DE3) pLysS to a soluble and active T7-tagged E2 (tE2): E2 plus fifteen extension residues from $N$-terminus. $\mathrm{tE} 2$ was purified to homogeneity by ammonium sulfate fractionation, gel filtration, and heat treatment. The sedimentation coefficient of $\mathrm{tE} 2$ was estimated $31 \mathrm{~S}$, suggesting that $\mathrm{tE} 2$ also comprises sixty subunits. $\mathrm{tE} 2$ was relatively stable; incubation at $60^{\circ} \mathrm{C}$ for $60 \mathrm{~min}$ affected its enzyme activity insignificantly, and $90 \%$ of original activity was recovered from $6 \mathrm{M}$ guanidine hydrochloride. tE2 was capable of spontaneously non-covalent association with the B. stearothermophilus E3: other component of the pyruvate dehydrogenase. Based on these results, tE2 was suggested useful for a model system to examine the stabilizing mechanism of an enzyme complex.
\end{abstract}

\section{INTRODUCTION}

The Bacillus stearothermophilus lipoate acetyltransferase [EC 2.3.1.12] (E2) comprises sixty identical subunits and forms a core of pyruvate dehydrogenase complex (PDC) (Perham, 1996; Domingo et al., 1999; Perham, 2000). Each subunit has three structural domains: catalytic domain (CD), E1/E3 binding domain (BD), and lipoyl domain (LD) from $C$ to $N$ termini. CD is solely responsible for a non-covalent aggregation of sixty subunits besides a catalytic function of E2. Through a BD, either tetrameric pyruvate decarboxylase [EC 1.2.4.1] (E1) or dimeric dihydrolipoamide dehydrogenase [EC 1.8.1.4] (E3) attaches non-covalently to a subunit so that PDC is a multienzyme complex having a molecular size of nearly ten megadalton. E1, E2, and E3 participate differently in the overall reaction catalyzed by PDC: the synthesis of acetyl CoA from pyruvate and CoA. E1 catalyzes the decarboxylative transfer of an acetyl group from pyruvate to thiamine diphosphate. The acetyl group is then transferred to a lipoyl group covalently

\footnotetext{
* Laboratory of Protein Chemistry and Engineering, Department of Genetic Resources Technology, Graduate School of Bioresource and Bioenvironmental Sciences, Kyushu University

** Corresponding author (E-mail: yaso@agr.kyushu-u.ac.jp)

*** Microbiology Laboratory, Faculty of Pharmaceutical Sciences, Fukuoka University, Fukuoka 814-0180
} 
attached to a lysine residue in LD: the center residue of a DKA motif (Dardel et al., 1993). The final acetyl transfer is that in CD from the lipoyl group to CoA, yielding a dihydrolipoamide group and acetyl CoA. The turnover of the overall reaction therefore requires the E3-catalyzed re-oxidation of the dihydrolipoamide group; E3 is a flavoprotein acting with the reduction of $\mathrm{NAD}^{+}$. We have been concerned with the stabilizing mechanism of a huge assembly composed of many polypeptides and have examined how PDC is disintegrated by several factors such as heat and potassium iodide (Hiromasa et al., 1994; Hiromasa et al., 1997; Aso et al, 1998). Since results from studies on stability of a component enzyme isolated from PDC are different from those using PDC, only based on knowledge of properties of free components, it is difficult to give an explanation of changes in PDC; these changes usually accompany the dissociation into and re-association of components (Hiromasa et al., 2000; Jung et al., 2002). Inter- and intra-protein interactions must be responsible for changes in PDC and become fairly complicated with increasing number of components. In this context, we have been in need of construction of a middle--scale model: a protein complex simpler than PDC, but far larger than a common oligomeric protein. The gene encoding E2 is cloned and sequenced (GenBank: 40038), and is expressed in Escherihia coli (Borges et al., 1990; Lessard et al., 1998). With reference to these results, we embarked on the preparation of $\mathrm{E} 2$ from the $B$. stearothermophilus (NCA 1503) spontaneous mutant, because this strain has been maintained in Kyushu University and because its fresh cells have been available. We examined the sequence of $\mathrm{E} 2$ gene from the mutant and constructed its overexpression system in $E$. coli. We furthermore purified resulting T7-tagged E2 and examined its properties; this E2 is abbreviated as tE2 in this paper.

\section{MATERIALS AND METHODS}

\section{Chemicals, plasmid, and genome DNA}

All chemicals used were of the highest grade commercially available. Sepharose CL-2B and Sephacryl S-400HR were obtained from Pharmacia LKB Biotechnology (Tokyo). The B. stearothermophilus diaphorase II (E3) was purchased from Unitika (Kyoto) and used without further purification. KOD' DNA polymerase and DNA ligation kit were from Takara Shuzo. Geneclean kit and Big Dye Terminator Cycle Sequencing kit were obtained from Bio101 (USA) and PE Applied Biosystems (USA), respectively. The cells of the B. stearothermophilus (NCA 1503) spontaneous mutant were kindly donated from Dr. M. Kimura (Faculty of Agriculture, Kyushu University). Chromosomal DNA of the cell was principally prepared according to the method of Barker (Barker, 1989). The E. coli BL21 (DE3) pLyS strain and the pET11a plasmid were obtained from Stratagene (La Jolla, USA).

\section{Cloning and sequencing of E2 gene}

$\mathrm{E} 2$ gene was amplified by the step-down polymerase chain reaction (PCR) according to the method of Hecker and Roux (Hecker and Roux, 1996). The reaction mixture comprised $700 \mathrm{ng}$ of the genome DNA, $200 \mathrm{mM}$ dNTPs, $100 \mathrm{pmol}$ of sense primer, 100 pmol antisense primer, and 2.5 units of KOD' DNA polymerase; the sense and antisense primers were 5'-GTGGATCCGTGCTTTTGAATTTAAGCTG-3' and 5'-GTGGATCCCAAC- 
TACCATCGTTTTACGCC-3', respectively. The mixture was incubated with thirty-five temperature cycles by the following (I) and (II) methods; each cycle in both the methods included successive three incubations at different temperatures for $30 \mathrm{sec}, 15 \mathrm{sec}$, and 15 $\mathrm{sec}$, respectively. First fifteen cycles were done by the method (I), using the following five temperature series: $95^{\circ} \mathrm{C}-74^{\circ} \mathrm{C}-72^{\circ} \mathrm{C} ; \quad 95^{\circ} \mathrm{C}-70^{\circ} \mathrm{C}-72^{\circ} \mathrm{C} ; \quad 95^{\circ} \mathrm{C}-66^{\circ} \mathrm{C}-72^{\circ} \mathrm{C}$; $95^{\circ} \mathrm{C}-62^{\circ} \mathrm{C}-72^{\circ} \mathrm{C} ; 95^{\circ} \mathrm{C}-58^{\circ} \mathrm{C}-72^{\circ} \mathrm{C}$. Each series was repeated three times. Residual twenty cycles were done by the method (II); every cycle was repeated, using $95^{\circ} \mathrm{C}-54^{\circ} \mathrm{C}-72^{\circ} \mathrm{C}$ temperature series. Resulting product was digested by Bam HI. The E2 gene was resolved by agarose gel electrophoresis, purified with Geneclean kit, and cloned into a pUC19 vector: pUC/E2. The DNA sequence of E2 gene in pUC/E2 was determined with an ABI PRISM 377 DNA sequencer using the forward and reverse M13/pUC sequencing primers, and a Big Dye Terminator Cycle Sequencing kit.

\section{Overexpression of E2 gene}

The pUC/E2 was digested with BamHI and resolved by agarose gel electrophoresis. Resulting E2 gene was purified using Geneclean kit and sub-cloned into a pET11a vector. $\mathrm{pET} / \mathrm{E} 2$ plasmid thus constructed was overexpressed in E. coli BL21 (DE3)pLysS; operation including cultivation in LB-amp medium at $37^{\circ} \mathrm{C}$ for $5 \mathrm{~h}$ after induction with $1 \mathrm{mM}$ isopropyl- $\beta$-D-thiogalactopyranoside (IPTG) was done according to the procedure described in the pET System Vectors and Hosts instruction manual (Stratagene, USA).

\section{Purification of tE2}

All procedures except for heat treatment were done at $4^{\circ} \mathrm{C}$. Unless otherwise noted, the buffer used for purification was $20 \mathrm{mM}$ sodium phosphate buffer ( $\mathrm{pH} 7$ ) containing $2 \mathrm{mM}$ EDTA and $0.15 \mathrm{mM}$ phenylmethanesulfonyl fluoride (standard buffer), and centrifugation was done for $30 \mathrm{~min}$ at $3,000-5,000 \times \mathrm{g}$. A protein solution was concentrated by the following method; proteins were precipitated by incubation in $50 \%$ saturation of $\left(\mathrm{NH}_{4}\right)_{2} \mathrm{SO}_{4}$ for $1 \mathrm{~h}$, re-suspended with a small amount of standard buffer, and centrifuged to remove insoluble matters. The overexpression of E2 gene was done by the method described above. The cells collected by centrifugation were re-suspended in a standard buffer and disrupted ten times by ultrasonic treatment: $30 \mathrm{sec}$ each. Cell debris was removed by centrifugation. Resulting supernatant was brought to $35 \%$ saturation of $\left(\mathrm{NH}_{4}\right)_{2} \mathrm{SO}_{4}$. After removal of precipitate by centrifugation, supernatant was concentrated and submitted to the gel filtration on a Sepharose CL-2B column $(2.5 \times 110 \mathrm{~cm})$; the column was pre-equlibrated and developed with a standard buffer. Active fractions were combined, concentrated, and filtered again through the same column. Active fractions were combined, concentrated, and incubated at $70^{\circ} \mathrm{C}$ for $5 \mathrm{~h}$. After centrifugation, resulting supernatant was dispensed and stored at $-30^{\circ} \mathrm{C}$.

\section{Assay of enzyme activity and analytical ultracentrifugation}

Enzyme activities of E2 and E3 were measured at $30^{\circ} \mathrm{C}$ by the methods reported previously (Hiromasa et al, 1993; Hiromasa et al., 1995). Analytical ultracentrifugation was done at $20,000 \mathrm{rpm}$ and $20^{\circ} \mathrm{C}$ by sedimentation velocity method, using a Beckman Optima XL-A ultracentrifuge equipped with An-60 Ti rotor and double sector cell $(12 \mathrm{~mm})$. Sedimentation pattern was monitored at $280 \mathrm{~nm}$ and analyzed with a Beckman 
XLAVEL program.

\section{Stability of tE2}

Stability of tE2 at various temperatures between $30^{\circ} \mathrm{C}$ and $95^{\circ} \mathrm{C}$ was examined by the following method: incubation of tE2 solution (standard buffer) for $60 \mathrm{~min}$, cooling on ice for $60 \mathrm{~min}$, and assay of enzyme activity at $30^{\circ} \mathrm{C}$. Stability of tE2 to guanidine hydrochloride ( $\mathrm{GdnHCl}$ ) was examined by the following method: incubation of $0.1 \mathrm{mg} / \mathrm{ml} \mathrm{tE} 2$ (standard buffer) at $4^{\circ} \mathrm{C}$ for $24 \mathrm{~h}$ in the presence of various amounts of $\mathrm{GdnHCl}$ and assay of enzyme activity at $30^{\circ} \mathrm{C}$. The amount of $\mathrm{GdnHCl}$ was confirmed by measuring refrative index (Pace et al., 1989). Effects of the removal of $\mathrm{GdnHCl}$ on tE2 were examined by measuring enzyme activity at $30^{\circ} \mathrm{C}$ after dialysis against a standard buffer at $4{ }^{\circ} \mathrm{C}$ for $48 \mathrm{~h}$.

\section{Preparation of tE2-E3 complex}

tE2 and E3 solutions were prepared with a standard buffer. Mixing ratio between tE2 and E3 was confirmed based on total UV absorbancy at $280 \mathrm{~nm}\left(\mathrm{~A}_{280}\right)$ of each solution; about $0.3 \mathrm{ml}$ of the mixture containing tE2 (total $\mathrm{A}_{280}=0.6$ ) and $\mathrm{E} 3$ (total $\mathrm{A}_{280}=1.2$ ) was prepared. The mixture was incubated for $30 \mathrm{~min}$ at room temperature and subjected to the gel filtration on a Sephacryl S- $400 \mathrm{HR}(1.5 \times 26 \mathrm{~cm})$ column at room temperature; the column was pre-equilibrated and developed with a standard buffer.

\section{RESULTS AND DISCUSSION}

\section{Cloning, sequencing, and overexpression of gene}

The E2 gene of the B. stearothermophilus (NCA 1503) original strain has an $1.3 \mathrm{~kb}-$ open reading frame (GenBank: 40038). With reference to the sequence of the gene, we designed the sense and antisense primers for amplification of the $\mathrm{E} 2$ gene from the $B$. stearothermophilus (NCA 1503) spontaneous mutant; both the sequences were further designed so that each primer included a $B a m \mathrm{HI}$ recognition site. Using these primers, the gene was successfully amplified by step-down PCR. Resulting products were digested by $B a m \mathrm{HI}$, and the E2 gene (1.3 kb) was purified by agarosegel electrophoresis. As shown in Fig. 1, the purified gene was ligated into pUC19 vector $(2.6 \mathrm{~kb})$ which had been also cut with $\mathrm{BamHI}$, and constructed a pUC/E2 plasmid $(3.9 \mathrm{~kb})$. Both the strands of the insert DNA in pUC19 were completely sequenced. As shown in Fig. 2, the gene had an open reading frame composed of 1305 bp encoding 434 amino acids (DDBJ nucleotide sequence accession number: AB044388). The gene was slightly larger than that of the original strain: 427 amino acids deduced (Borges et al., 1990; GenBank: 40038). Comparison of deduced amino acid sequence of the spontaneous mutant with that of original strains is illustrated in Fig. 3. We hereinafter follow the numbering of amino acid residue for the E2 gene from the original strain (GenBank: 40038). There was a single LD (A-1 to F-85) including a DKA motif (41 to 43) in the sequence (Neveling et al., 1998), suggesting occurence of a single lipoyl group. Within the region (A-1 to E-89) including this LD, there was no difference in sequences between the two strains. Only one replacement from $\mathrm{V}-157$ to $\mathrm{I}-157$ was within the region (P-124 to $\mathrm{K}-171$ ) including $\mathrm{BD}$ (V-128 to A-170). Although seven residues within $C D$ (E-192 to A-427) were different from those of original strains, a sequence around a catalytic $\mathrm{H}-398$ was well conserved. Relatively 


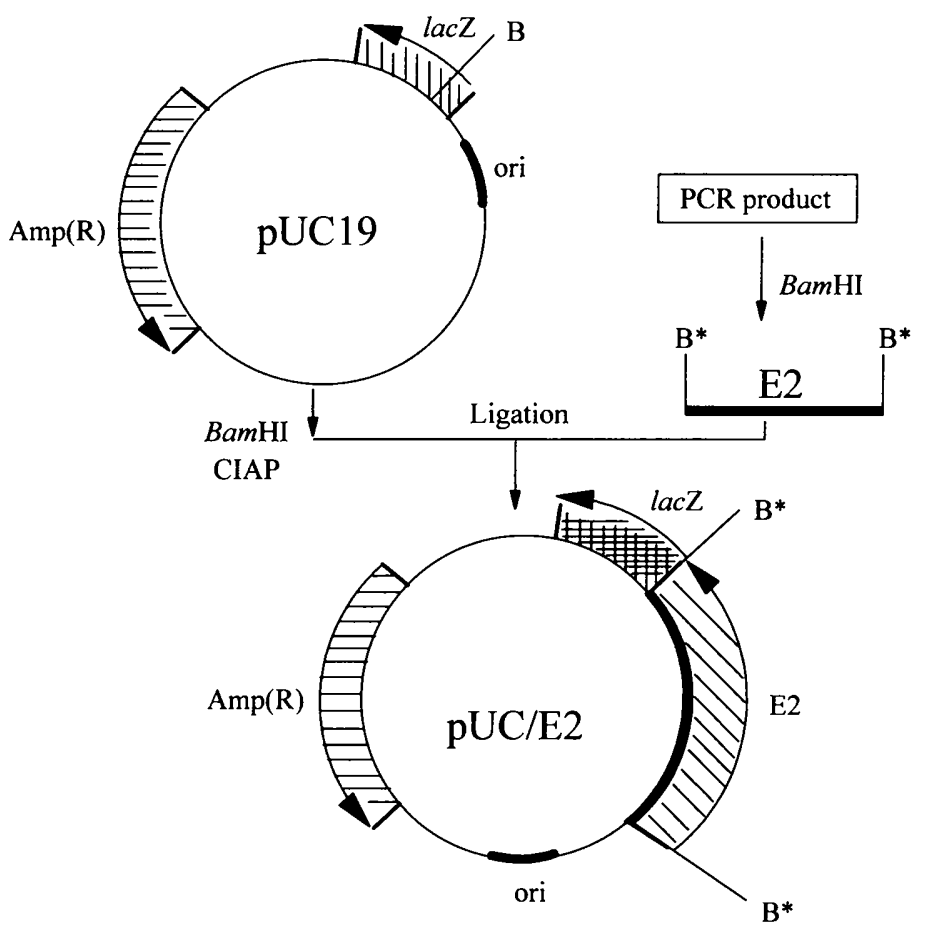

Fig. 1. Construction scheme of pUC/E2. Shadowed portion and arrow of circular arc indicate gene and its orientation, respectively. CIAP, calf intestinal alkaline phosphatase; $\mathrm{B}, \mathrm{Bam} \mathrm{HI}$ site; $\mathrm{B}^{*}$, BamHI site introduced; ori, origin of ColE1 plasmid replication; lacZ, gene encoding $\beta$-galactosidase; Amp(R), ampicillin resistance gene.

large difference in sequences was in a flexible linker region between adjacent domains; gaps were also in the region between $\mathrm{BD}$ and $\mathrm{CD}$. Based on these results, it was suggested that drastic mutations are never induced and that highly conserved sequences in the region corresponding to a structural domain are significant.

As shown in Fig. 4, E2 gene was purified from BamHI digestion products of the pUC/E2 plasmid by agarose gel electrophoresis and sub-cloned into a pET11a vector $(5.6 \mathrm{~kb})$. Resulting pET/E2 plasmid $(6.9 \mathrm{~kb})$ was expressed in the E. coli BL21 (DE3) pLysS strain. The addition of IPTG to a culture medium induced the expression of E2 as a soluble and active enzyme efficiently. E2 thus overexpressed was a T7-tagged E2: tE2. As shown in Fig. 5 , at a $N$-terminus, amino acid sequence of tE2 was deduced fifteen residues larger than that deduced from E2 gene (Fig. 3). Our several trials to prepare an E2 without the T7 tag or with other tag were unsuccessful and, so far, an efficient expression of the gene is only performed with the pET/E2. We used the pET11a vector to amplify the whole E2 gene. On the other hand, the genes of original strain encoding the $\mathrm{N}$ - and $C$-terminal regions of E2 are separately amplified by splice overlap extension PCR 


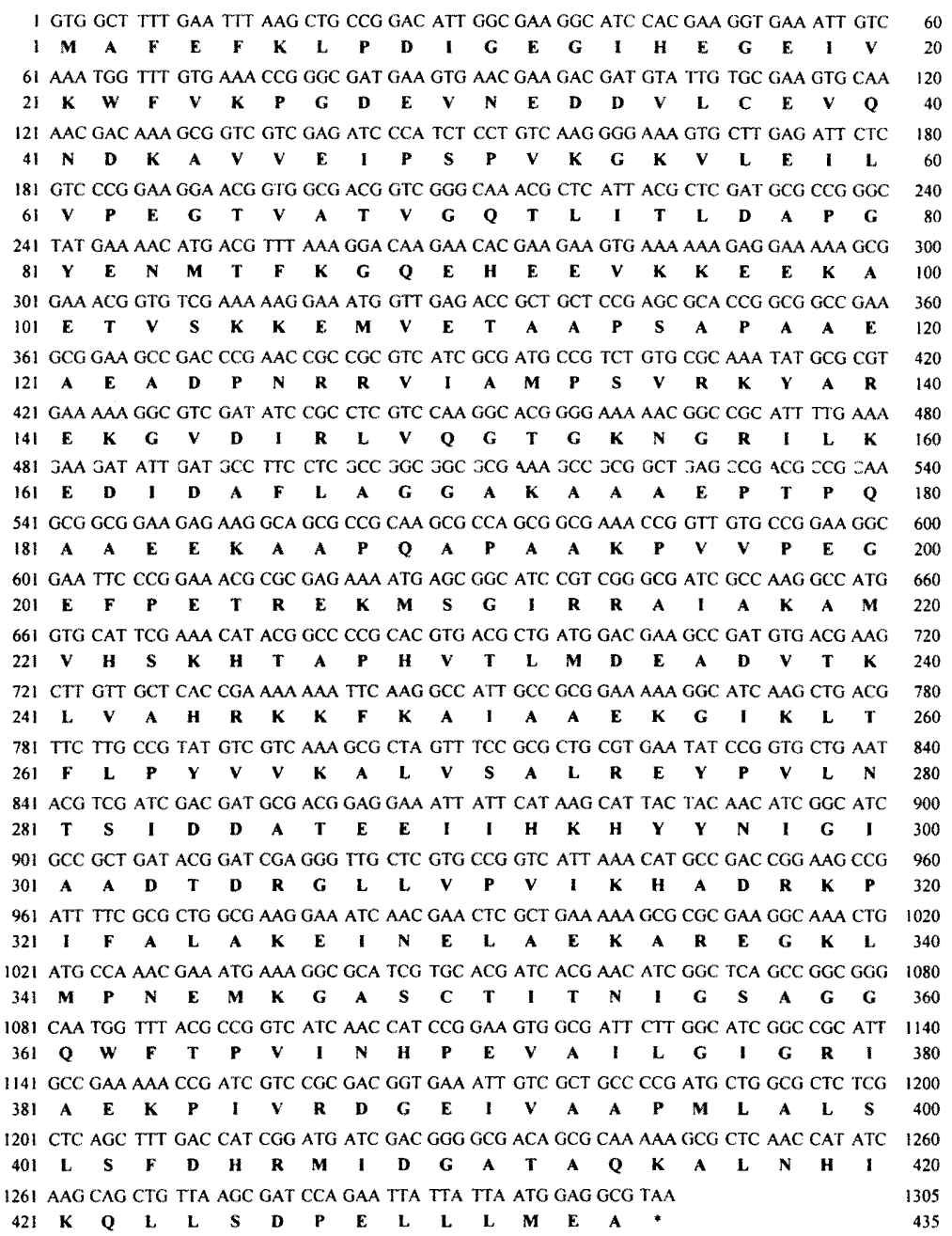

Fig. 2. Nucleotide sequence of E2 gene and its amino acid sequence deduced. Termination codon is indicated by asterisk.

method, and then, an expression plasmid is constructed by connecting the two genes (Lessard et al., 1998).

\section{Purification and characterization of E2}

We purified tE2 by a fractionation between $35 \%$ and $50 \%$ saturation of ammonium sulfate, two consecutive chromatographies using Sepharose CL $-2 B$, and a heat treatment at $70^{\circ} \mathrm{C}$ for $5 \mathrm{~h}$. By this procedure, $130 \mathrm{mg}$ of $\mathrm{tE} 2(162 \mathrm{units} / \mathrm{mg}$ ) was purified from $1800 \mathrm{ml}$ of a culture medium. Limited proteolysis of PDC by V8 protease yields $\mathrm{E} 2$ inner core 


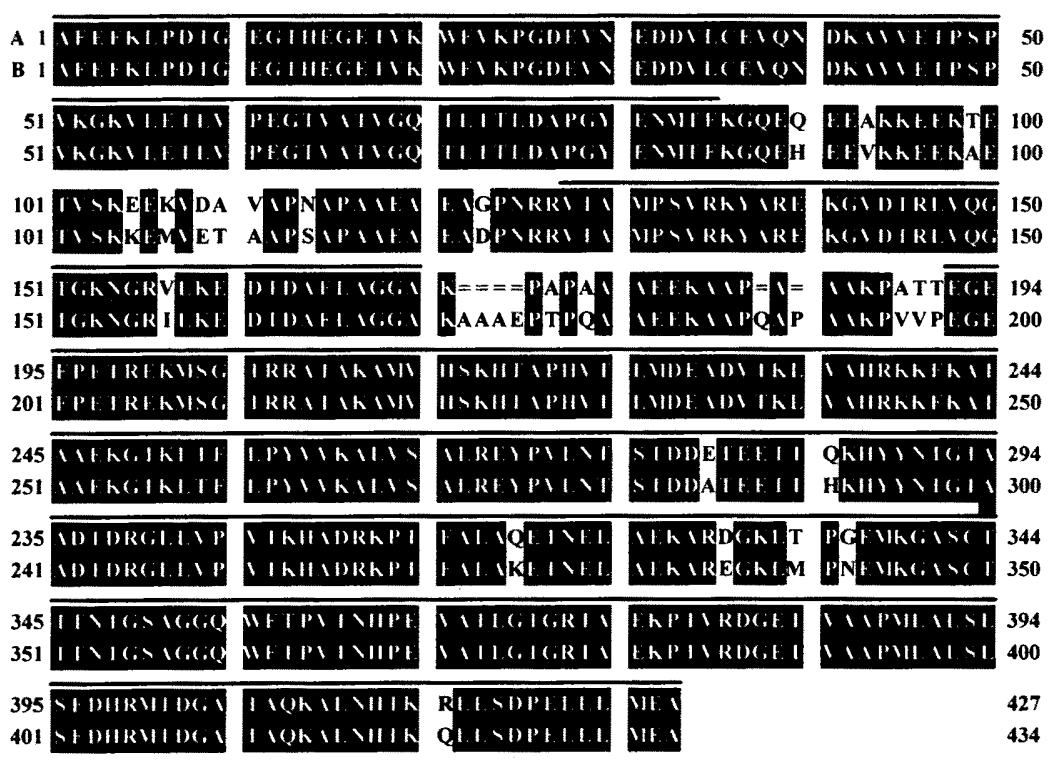

Fig. 3. Comparison of deduced amino acid sequence of $\mathrm{E} 2$ from the $B$. stearothermophilus NCA1503 (A) with that from its spontaneous mutant (B). Identical amino acid residue is highlighted on a black background. A gap is indicated by an equal sign. Lines above a vertical pair of residues indicate the three domains: $\mathrm{LD}(\mathrm{A}-1$ to $\mathrm{F}-85), \mathrm{BD}(\mathrm{V}-128$ to $\mathrm{A}-170)$, and $\mathrm{CD}(\mathrm{E}-192$ to $\mathrm{A}-427)$.

(E2ic) that is an assembly of sixty CD polypeptides (Perham and Wilkie, 1980). Previously we examined the GdnHCl-induced denaturation of E2ic and found that a pre-incubation of E2ic at $70^{\circ} \mathrm{C}$ and cooling on ice affect its enzyme activity and thermostability insignificantly, but improve the recovery of the activity from GdnHCl-induced denaturation (Hiromasa et al, 1998; Aso et al., 2001). We therefore adopted the heat treatment in the purification procedures of $\mathrm{tE} 2$, although a stabilizing mechanism of E2ic is still under investigation. This treatment might be useful for inactivation of $E$. coli original enzymes including proteins showing affinity for tE2 overexpressed. We confirmed the purity of tE2 by SDS PAGE, comparing with the electrophoretic mobility of an E2 component of PDC separately purified from the B. stearothermophilus cells (data not shown). The sedimentation coefficient $\left(\mathrm{S}^{\circ}{ }_{20, w}\right)$ of tE2 was estimated $31 \mathrm{~S}$. The sedimentation coefficient of E2ic isolated from PDC is 30S-27S (Packman et al, 1984; Hiromasa et $a l, 1998)$. The molecular size of tE2 is estimated larger than E2ic, but contribution of LD and $\mathrm{BD}$ to sedimentation velocity might be less than that of $\mathrm{CD}$, because these domains are connected with flexible region and protruded from the core portion corresponding to E2ic. It was therefore suggested that the value of the sedimentation coefficient of $t E 2$ is similar to that of E2ic and that tE2 also comprises sixty subunits. Since the overexpression of tE2 was never done under any lipoylation conditions such as a use of culture medium supplemented with lipoic acid, tE2 was supposed lipoyl-deficient (Wallis and 


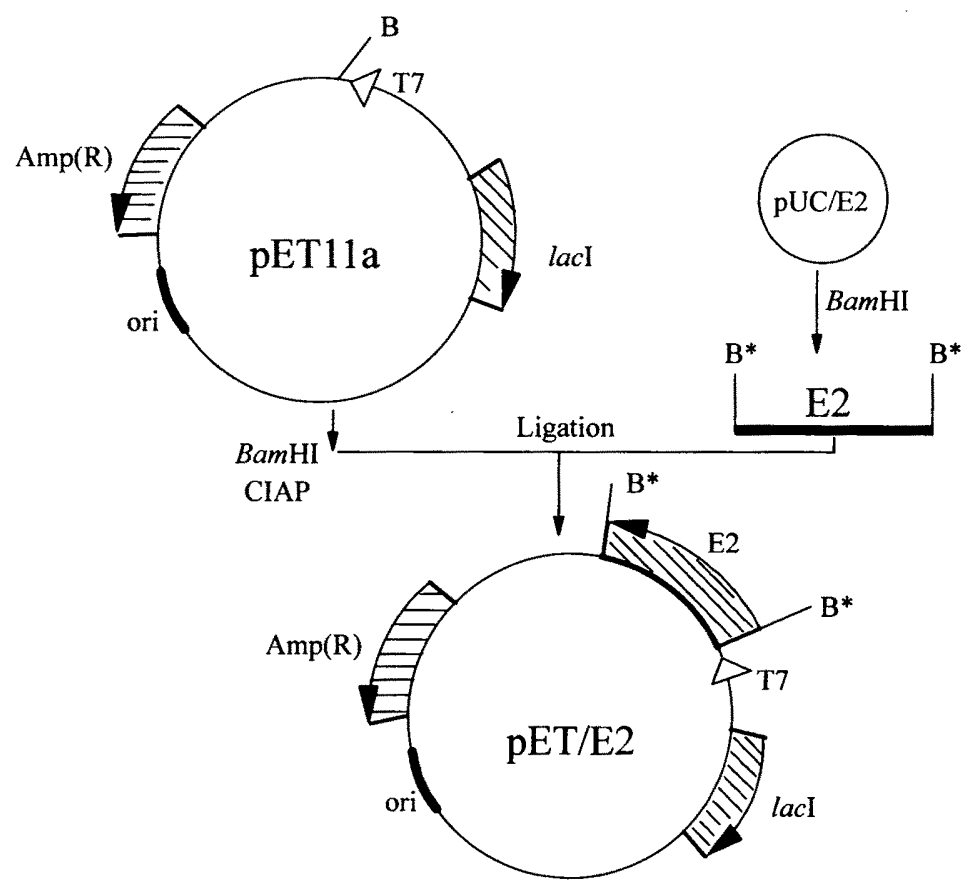

Fig. 4. Construction scheme of pET/E2. Shadowed portion and arrow of circular arc indicate gene and its orientation, respectively. CIAP, calf intestinal alkaline phosphatase; $\mathrm{B}$, BamHI site; $\mathrm{B}^{*}, \mathrm{BamHI}$ site introduced; ori, origin of ColE1 plasmid replication; lacI, gene encoding lac repressor; T7; T7 promoter; $\operatorname{Amp}(R)$, ampicillin resistance gene.

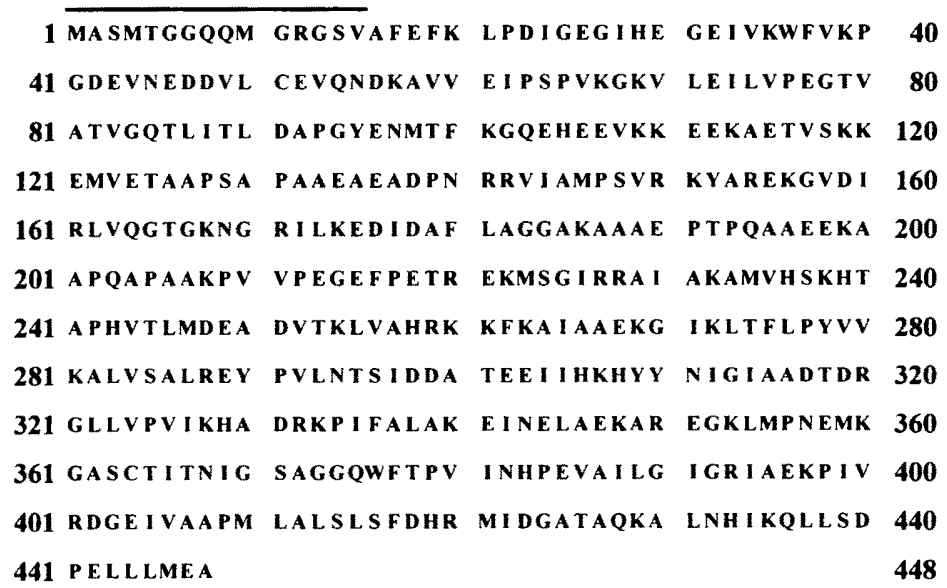

Fig. 5. Deduced amino acid sequence of tE2. A bar indicates $N$-terminal extension sequence. 


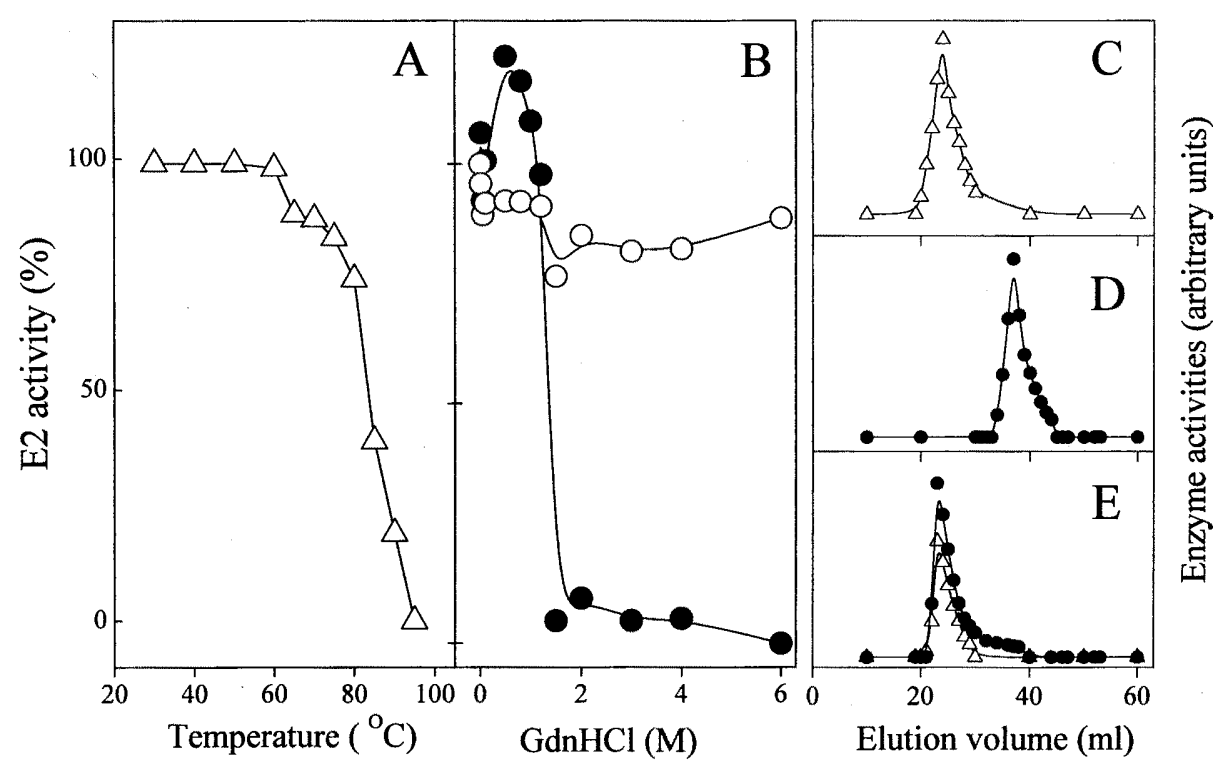

Fig. 6. Temperature- or GdnHCl-induced changes in enzyme activity of tE2 and complex formation between tE2 and E3. Panel A: temperature-induced inactivation of tE2. Residual activities $(\triangle)$ after incubation at various temperatures are plotted as values relative to the activity without incubation. Panel B: GdnHCl-induced changes in activity of tE2; E2 activity after incubation with $\mathrm{GdnHCl}(\mathbf{O})$; $\mathrm{E} 2$ activity after the incubation and subsequent removal of $\mathrm{GdnHCl}$ by dialysis (O). Activities are plotted as values relative to the activity in the absence of GdnHCl. Panel C-E: gel-filtration profiles of tE2 (C; $\triangle$, E2 activity), E3 (D; $\mathbf{O}$, $\mathrm{E} 3$ activity), and their mixture (E; $\triangle, \mathrm{E} 2$ activity; $\mathrm{O}$, E3 activity).

Perham, 1994; Lessard et al., 1998).

We examined the thermostability of tE2 by incubating at various temperatures, cooling, and measuring residual activity. As shown in Fig. 6A, tE2 lost about 25\% of its original activity by incubation at $80^{\circ} \mathrm{C}$ for $60 \mathrm{~min}$. Only based on these results, there might be no drastic difference in thermostability between $\mathrm{tE} 2$ and E2ic, and tE2 was highly resistant to heat (Aso et al., 2001). We also examined the effects of GdnHCl on tE2. After incubation at $4{ }^{\circ} \mathrm{C}$ for $24 \mathrm{~h}$ in the presence of $\mathrm{GdnHCl}$, an enzyme activity was measured. Although GdnHCl at concentrations less than $1.0 \mathrm{M}$ had a tendency to improve the activity, as shown in Fig. 6B, tE2 lost almost all its activity in $1.5 \mathrm{M} \mathrm{GdnHCl}$. Gradual removal of $\mathrm{GdnHCl}$ by dialysis restored at least $80 \%$ of its original activity even after incubation in $6 \mathrm{M} \mathrm{GdnHCl}$. Since the assay of enzyme activity dilutes GdnHCl rapidly, our observations might include changes induced by rapid dilution. It was therefore implied that the rapid dilution and the gradual removal induce irreversible and reversible changes 
in tE2, respectively. We also monitored the intensity of light scattering (at $540 \mathrm{~nm}$ ) of tE2 in the presence of $\mathrm{GdnHCl}$ and found that the intensity decreases with increasing amount of $\mathrm{GdnHCl}$ and that $\mathrm{GdnHCl}$ at concentrations above $1.5 \mathrm{M}$ quenches the scattering (data not shown). Based on these results, tE2 was suggested completely dissociated in $1.5 \mathrm{M}$. E2ic of original strain is expressed in $E$. coli and purified as an active sixty-mer; this E2ic comprises residues from 173 to 427 (Allen et al., 1997). The E2ic dissociated into monomers in the presence of $6 \mathrm{M} \mathrm{GdnHCl}$ is reassociated into fully active species by dialysis against a phosphate buffer with stepwise decrease in $\mathrm{GdnHCl}$ content. In our experiments, $\mathrm{GdnHCl}$ was never removed by such a carefully designed method. Irreversible loss in activity of tE2, therefore, might occur partially.

Finally we examined whether tE2 is capable of binding non-covalently to the $B$. stearothermophilus E3. tE2, E3, and their mixture were analyzed by gel filtration. The peaks of E2 and E3 activities were detected at elution volumes of $24 \mathrm{ml}$ and $37 \mathrm{ml}$, respectively (Fig. 6C \& 6D); in both cases, an elution profile of activity was overlapped with that of protein (data not shown). When the mixture of tE2 with E3 was prepared in the total $\mathrm{A}_{280}$ ratio $\mathrm{tE} 2 \mathrm{E} 3=1: 2$ and analyzed, each of $\mathrm{E} 2$ and $\mathrm{E} 3$ activities was eluted as a single peak at $23 \mathrm{ml}$ (Fig. 6E); proteins were also eluted as a single peak at the same volume (data not shown). This volume was at the exclusion limit of the Sephacryl column and smaller than that of tE2. Upon mixing in the total $\mathrm{A}_{280}$ ratio tE2:E3=1:5, E2 activity was also peaked at $23 \mathrm{ml}$, but $\mathrm{E} 3$ activity was split into the two peaks at $23 \mathrm{ml}$ and $37 \mathrm{ml}$ (data not shown). Based on these results, tE2 was strongly suggested to form a complex with multiple copies of E3 molecules.

\section{ACKNOWLEDGMENT}

We are grateful to Dr. N. Kashige (Fukuoka University) for his technical assistance throughout this work.

\section{REFERENCES}

Allen, M. D. and R. N. Perham 1997 The catalytic domain of dihydrolipoyl acetyltransferase from the pyruvate dehydrogenase multienzyme complex of Bacillus stearothermophilus. Expression, purification and reversible denaturation. EFEBS Lett., 413: 339-343

Aso, Y., Y. Hiromasa, Y. Aikawa, K. Meno and M. Ishiguro 1998 Potassium iodide-induced changes in pyruvate dehydrogenase complex from Bacillus stearothermophilus. Biosci. Biotechnol. Biochem., 62: $108-116$

Aso, Y., A. Nakajima, K. Meno and M. Ishiguro 2001 Thermally induced changes of lipoate acetyltransferase inner core isolated from the Bacillus stearothermophilus pyruvate dehydrogenase complex. Biosci. Biotechnol. Biochem., 65: 698-701

Barker, D. G. 1982 Cloning and amplified expression of the tyrosyl-tRNA synthetase genes of Bacillus stearothermophilus and Escherichia coli. Eur. J. Biochem., 125: $357-360$

Borges, A., C. F. Hawkins, L. C. Packman and R. N. Perham 1990 Cloning and sequence analysis of the genes encoding the dihydrolipoamide acetyltransferase and dihydrolipoamide dehydrogenase components of the pyruvate dehydrogenase multienzyme complex of Bacillus stearothermophilus. Eur. J. Biochem., 194: $95-102$

Dardel, F., A. L. Davis, E. L. Laue and R. N. Perham 1993 The three-dimensional structure of the lipoyl domain from Bacillus stearothermophilus pyruvate dehydrogenase multienzyme complex. J. $\mathrm{Mol}$. Biol., 229: 1037-1048

Domingo, G. J., H. J. Chauhan, I. A. D. Lessard, C. Fuller and R. N. Perham 1999 Self-assembly and 
catalytic activity of the pyruvate dehydrogenase multienzyme complex from Bacillus stearothermophilus. Eur. J. Biochem., 266: 1136-1146

Hecker, K. H. and K. H. Roux 1996 High and low annealing temperatures increase both specificity and yield in touchdown and stepdown PCR. BioTechniques, 20: 478-485

Hiromasa, Y., Y. Aso and S. Yamashita 1993 Purification of the pyruvate dehydrogenase complex from an extreme thermophile, Bacillus caldolyticus, and its thermal stability. Biosci. Biotechnol. Biochem., 57: $1062-1066$

Hiromasa, Y., Y. Aso and S. Yamashita 1994 Thermal disassembly of pyruvate dehydrogenase multienzyme complex from Bacillus stearothermophilus. Biosci. Biotechnol. Biochem., 62: 1904-1905

Hiromasa, Y., Y. Aso, S. Yamashita and Y. Aikawa 1995 Homogeneity of the pyruvate dehydrogenase multienzyme complex from Bacillus stearothermophilus. J. Biochem., 117: 467-470

Hiromasa, Y., Y. Aso, S. Yamashita, Y. Aikawa and M. Ishiguro 1997 Further studies on thermal denaturation of pyruvate dehydrogenase complex from Bacillus stearothermophilus. Biosci. Biotechnol. Biochem., 61: 1126-1132

Hiromasa, Y., Y. Aso, K. Mayanagi, Y. Inoue, T. Fujisawa, K. Meno and T. Ueki 1998 Guanidine hydrochloride-induced changes of the E2 inner core of the Bacillus stearothermophilus pyruvate dehydrogenase complex. J. Biochem., 123: 564-567

Hiromasa, Y., Y. Aso, S. Yamashita and K. Meno 2000 Thermally induced disintegration of the Bacillus stearothermophilus dihydrolipoamide dehydrogenase. Biosci. Biotechnol. Biochem., 64: 1923-1929

Jung, H-I., S. J. Bowden, A. Cooper and R. N. Perham 2002 Thermodynamic analysis of the binding of component enzymes in the assembly of the pyruvate dehydrogenase multienzyme complex of Bacillus stearothermophilus. Protein. Sci., 11: 1091-1100

Lessard, I. A. D., G. J. Domingo, A. Borges and R. N. Perham 1998 Expression of genes encoding the E2 and E3 components of the Bacillus stearothermophilus pyruvate dehydrogenase complex and the stoichiometry of subunit interaction in assembly in vitro. Eur. J. Biochem., 258: 491-501

Neveling, U., S. Bringer-Meyer and H. Sahm 1998 Gene and subunit organization of bacterial pyruvate dehydrogenase complexes. Biochim. Biophys. Acta, 1385: 367-372

Pace, C. N., B. A. Shirley and J. A. Thomson 1989 Measuring the conformational stability of a protein. In "Protein structure", ed. by T. E. Creighton, IRL Press, Oxford, pp. 311-330

Packman, L. C., R. N. Perham and G. C. K. Roberts 1984 Domain structure and 'H-n.m.r. spectroscopy of the pyruvate dehydrogenase complex of Bacillus stearothermophilus. Biochem. J., 217: 219-227

Perham, R. N. and A. O. M. Wilkie 1980 Inner core and domain structure of the pyruvate dehydrogenase multienzyme complex of Bacillus stearothermophilus. Biochem. Int., 1: 470-477

Perham, R. N. 1996 Interaction of protein domains in the assembly and mechanism of 2-oxo acid dehydrogenase multienzyme complexes. In "Alpha-keto acid dehydrogenase complexes", ed. by M. S. Patel, T. E. Roche and R. A. Harris, Birkhaeuser Verlag, Basel, pp. 1-15

Perham, R. N. 2000 Swinging arms and swinging domains in multifunctional enzymes: catalytic machines for multistep reactions. Annu. Rev. Biochem., 69: 961-1004

Wallis, N. G. and R. N. Perham 1994 Structural dependence of post-translational modification and reductive acetylation of the lipoyl domain of the pyruvate dehydrogenase multienzyme complex. $J$. Mol. Biol., 236: 209-216 